\title{
Spectral Description of Colored Cellulose Textile with Date Pits Extract: Study of the Fluorescence Characters
}

\author{
NAOUFEL BEN HAMADI ${ }^{1,2 *}$ and AHLEM GUESMI ${ }^{1,3}$ \\ ${ }^{1}$ Chemistry Department, College of Science, IMSIU (Imam Mohammad Ibn Saud Islamic University), \\ Riyadh 11623, kingdom of Saudi Arabia. \\ ${ }^{2}$ Laboratory of Synthesis Heterocyclic and Natural Substances, Faculty of Sciences of Monastir, \\ Boulevard of Environment, 5000 Monastir, Tunisia. \\ ${ }^{3}$ Textile Engineering Laboratory, Higher Institute of Technological Studies of Ksar, Hellal, Tunisia. \\ ${ }^{*}$ Corresponding author E-mail: bh_naoufel@yahoo.fr \\ http://dx.doi.org/10.13005/ojc/370504
}

(Received: June 14, 2021; Accepted: September 01, 2021)

\begin{abstract}
This work presents to evaluation the fluorescence parameters of cellulose dyed with date pits extract. Fluorescence measurements have been advanced on cellulose models before and later dyeing. The emission spectrum of the nondyed cellulose fibers not demonstrate any bond and, in the opposing, dyed cellulose sample existing important photoluminescence characters and the maximum value was noted at $672 \mathrm{~nm}$.
\end{abstract}

Keywords: Fluorescence property, Date pits extract, Dyeing, Cellulose fabric.

\section{INTRODUCTION}

Until the end of the last century, natural dyes were the only source of color for all textiles commonly used by humans. These dyes were also used for dyeing wood, feathers, etc., and they provided part of the pigments used in painting and were also of great importance in cosmetics, pharmaceuticals and food. Unlike synthetic dyes, natural dyes usually do not consist of just one coloring molecule. They almost always result from a combination of several coloring molecules, usually from different chemical groups. This gives them a subtlety of unparalleled tones which explains why the artisan dyers of many civilizations have remained attached to the use of natural dyes for their most prestigious textile productions or those most loaded with symbolic and religious meaning. However, the accidental discovery in 1856 of a synthetic dye, mauveine, initiated the end of the traditional art of dyes, especially since they present a difficulty in standardizing and reproducing the results. Therefore, the transition to synthetic dyes was rapid as the new dyes were safe, convenient, and generally less expensive industrially.

The natural dye is combined in the human mind with the notions of environmental and physiological consciousness. This idea alone is sufficient to explain the rebirth of this art, as well as the marked tendency of several researchers to switch from a natural artisan dye to an academic

This is an Open Access article licensed under a Creative Commons license: Attribution 4.0 International (CC- BY). Published by Oriental Scientific Publishing Company @ 2018

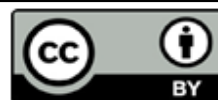


natural dye. In addition to the brilliance and harmony of the colors generated by natural dyes, these are, more than synthetic dyes, renewable sources as they are mostly biodegradable ${ }^{1-7}$. For those motives, numerous works have projected natural colorants as a substitute to the prepared ones. Dates represent share of a fashionable existence amongst the population of the Middle Eastern ${ }^{8}$. In adding, there are additional possible applications counting oil mining from the date pits or exploitation them as a dietary-fiber benefactor in bakeshop preparations $^{9}$. Fluorescence is a natural emission which translates the capacity of certain pigments to re-emit light at certain particular wavelengths by the reverse process of absorption. We're talking about spontaneous broadcast. Fluorescence is widely used in the biology as a non-invasive analytical tool, particularly since the discovery of fluorescent molecules that can be used as probes in place of radioactive elements. In the case of plants, this technique is all the more interesting than the leaves naturally contain fluorescent molecules called fluorophores ${ }^{10}$.

This study was established in order to describe the fluorescence characters of cellulose fibers dyed with date pits extract.

\section{EXPERIMENTAL}

\section{MATERIALS AND METHODS}

\section{Date nucleus}

Discarded date nucleus were collected and cleaned with tap water. Then, they were dried from the residual water at room temperature. After that, they were frozen at $-50^{\circ} \mathrm{C}$ for $3 \mathrm{~h}$ and finally freezedried. A hammer mill was then used to ground the freeze-dried date-nucleus, and the derived powder was kept at $-50^{\circ} \mathrm{C}$ for further uses.

\section{Cellulose fabric}

Commercially bleached cotton fabric with the following specifications was kept for developing the dyeing experiments (knitted cotton of $150 \mathrm{~g} / \mathrm{m}^{2}$ ).

\section{Methods \\ Extraction of dye}

The freeze-dried date-pits powder $(1 \mathrm{~g})$ was extracted with $100 \mathrm{~mL}$ of an extraction solvent at temperatures of 25 and $50^{\circ} \mathrm{C}$. The used solvents were (acetone: water) in the ratio (1:1) (Suresh et al., 2013). Conventional extraction was carried out with a magnetic stirrer hot plate. The extraction was carried out for $2 \mathrm{~h}$ in a conical flask tailored with a refrigerant to avoid any losses of solvent. Filtrate was evaporated in vacuum until reducing the volume of each extract from 100 to $50 \mathrm{~mL}$.

\section{HPLC analysis}

HPLC analysis of phenolic acids in date nucleus was established affording to the technique presented by Chang Lee and Mohamed Al-Farsi with modification (Al-Farsi et al., 2008). 20 milliliters of (methanol: $15 \%$ acetic acid) was additional to $0.5 \mathrm{~g}$ of freeze-dried date-pits powder. The mixture was stirred for $5 \mathrm{~min}$, then sonicated for 30 minutes. Later that, 5 milliliter of purified water and 5 milliliter of sodium hydroxide $(5 \mathrm{M})$ were poured. The all has been effervesced with nitrogen, and strongly stirred for $4 \mathrm{~h}$ at room temperature. The $\mathrm{pH}$ of the presented solution has been adjusted to 2, then the released phenolic acids were extracted three times with 25 milliliters of (diethyl ether: ethyl acetate) (50:50). The resulted mixture was evaporated, and then liquified in 2 milliliters of $\mathrm{MeOH}$. The solution was then filtered through a micro filter (porosity of 0.45 $\mu \mathrm{m})$. Then $20 \mu \mathrm{L}$ of the solution was inserted into a high-performance liquid chromatography apparatus (Merck) equipped with Prodigy ODS-2 column. HPLC technique were as follows: Solvent $A$ was $50 \mathrm{mM}$ phosphoric acid, $\mathrm{pH} 2.5$, and solvent $B$ was acetonitrile. The elution gradient was as shadows: 0-5 min, isocratic elution $95 \% \mathrm{~A}$ and $5 \% \mathrm{~B} ; 5-55 \mathrm{~min}$, linear gradient $80 \% A$ and $20 \% B ; 55-60$ min, linear gradient $95 \% \mathrm{~A}$ and $5 \% \mathrm{~B}$. Flow rate of the mobile phase was $0.9 \mathrm{~mL} / \mathrm{minute}$. The wavelengths of the diode array detector were set at 254, 270, 280 and $329 \mathrm{~nm}$ for monitoring of phenolic acids.

\section{Determination of total phenolic amount Spectrophotometric}

Determination of the total phenolic amount (TPC) was complete with the Folin-Ciocalteu technique using gallic acid as a standard (Yoo et al., 2004): 1 milliliter of extract dye was poured in 1 milliliter of Folin-Ciocalteu's reactive and allowable to react for 10 minutes. Then, 15 milliliter of $10 \% \mathrm{NaCO}_{3}$ solution were poured. Afterward that, the ending volume was complete up to 25 milliliter with deionized water. After keeping the whole reacting within $1 \mathrm{~h}$ at room temperature, the absorbance of the solution was 
measured at $750 \mathrm{~nm}$. The total phenolic concentration was expressed as milligrams of gallic acid equivalents per gram of date pits powder.

\section{Dyeing procedure}

Dyeing experiments were developed in a research laboratory using Ahiba Datacolour machine with the prepared solutions at a liquor to good ratio of 40:1. For all experiments, $\mathrm{pH}$ value was fixed to 4 , temperature to $90^{\circ} \mathrm{C}$ and for a constant duration of 90 minutes. The colored samples were lastly washed with cold water and dehydrated at moderate temperature.

\section{Determination of color intensities quantities}

The color produce of the colored samples was estimated by bright reflectance quantities using SF 300 spectrophotometer apparatus. Comparative color intensities (K/S values) were resolute using the Kubelka-Munk equation.

$\mathrm{K} / \mathrm{S}=(1-\mathrm{R})^{2} /(2 \mathrm{R})$

\section{Spectral characterization of cellulose fabric}

The spectra of the fluorescence of dyed wool fibers were attained exploitation with fluorescence spectrophotometer (Perkine-Elmer LS-3).

\section{RESULTS AND DISCUSSION}

\section{Extraction of dye from date pits}

The UV-spectrum of the dye pits extract illustrations a attitude of absorption in the visible range amongst 465 to $515 \mathrm{~nm}$, this demonstrations that the aqueous solution offerings a combination of dyed molecules ${ }^{4}$.

\section{Determination of phenolic compounds}

Figure 1 demonstrations the phenolic acid compounds of pits date extract. Shahidi and Naczk demonstrated that the phenolic acid molecules checked in fruits are frequently current in certain formulae, and they projected a action of hydrolysis with strong acid to liber them in order to agree their quantification. The retention times as well as the documentation of the phenolic molecules are showed in Table 1. A nine phenolic acids compounds were identified. Caffeic and protocatechuic were the focal phenolic molecules noticed. The overhead consequences were in agreement with the results described in the works. The total phenol contents and the total flavonoid compounds were calculated for the conventional technique. The phenol compounds were $77\left(\mathrm{mg} \mathrm{GA} / \mathrm{g}\right.$ date stone powder) at $50^{\circ} \mathrm{C}$. In totaling, the flavonoid compounds was $56(\mathrm{mg}$ catechin/g date stone powder) at $50^{\circ} \mathrm{C}$.

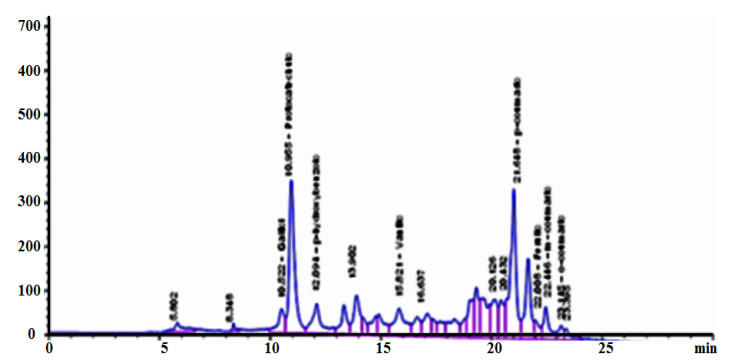

Fig. 1. HPLC chromatogram of phenolic acids Table 1: HPLC retention time

\begin{tabular}{ccc}
\hline Peaks & Rt (min) & Identified component \\
\hline 1 & 10.522 & Gallic acids \\
2 & 10.955 & Protocatechuic acids \\
3 & 12.094 & p-hydroxybenzoic acids \\
4 & 15.821 & Vanillic acids \\
5 & 20.999 & Caffeic acids \\
6 & 21.648 & p-coumaric acids \\
7 & 22.008 & Ferulic acids \\
8 & 22.446 & m-coumaric acids \\
9 & 23.145 & o-coumaric acids \\
\hline
\end{tabular}

Dyeing of cellulose with date pits extract

Cellulose fabric was dyed with date pits extract; consequences are showed in Table 1. It is exposed from the taking pictures of the colored textile and from the positive values of $a^{*}$ and $b^{*}$ that the type of all colored examples lies in the red-yellow zone ${ }^{11,12}$.

\begin{tabular}{|c|c|c|c|}
\hline \multirow[b]{2}{*}{$a^{*}$} & \multicolumn{3}{|c|}{$\mathrm{CIE} \mathrm{a}^{*}, \mathrm{~b}^{*}, \mathrm{~L}^{*}$ and $\mathrm{K} / \mathrm{S}$ values } \\
\hline & $b^{*}$ & $L^{*}$ & $\mathrm{~K} / \mathrm{S}$ \\
\hline 8.57 & 13.81 & 55.81 & 14.82 \\
\hline
\end{tabular}

\section{Spectral propriety of dyed cellulose fibers}

This part of the work was therefore advanced with a view to verifying whether the extract of date pits communicates its fluorescence property to the textile support on which it is fixed.

\section{Principle and experimental device for measuring optical properties}

This optical characterization involves three steps on a very short time scale: the absorption of photons, the thermalization of the carriers created and the return to equilibrium 
by radiative recombination. The experimental bench used for measuring the fluorescence of cellulose examples dyed with date pits is shown diagrammatically in Figure 2.

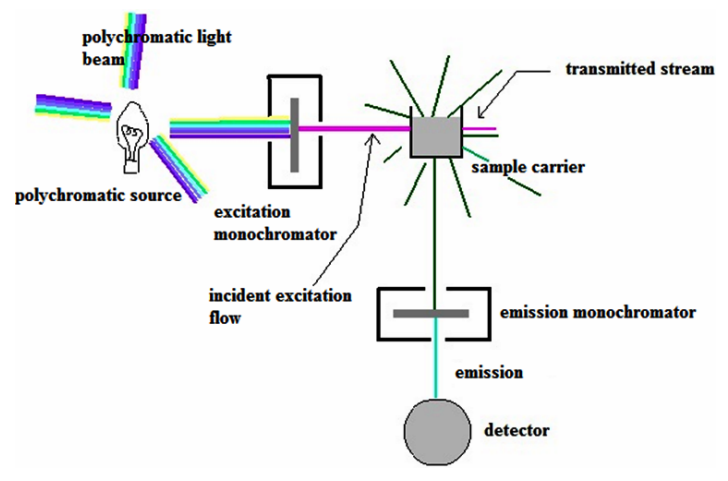

Fig. 2. Fluorescence test bench for dyed samples

\section{Study of optical properties}

This part study was advanced in directive to examine the chromatic properties owed to the connections of date pits extract with cellulose fiber. The photography of the colored cellulose textile is exposed in Figure 3.

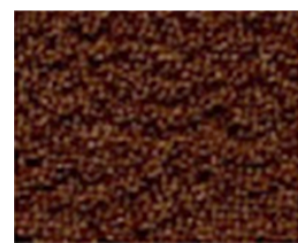

Fig. 3. Photograph of a cellulose sample dyed with date pits extract

It would be renowned that the fluorescence characters of the colored cellulose fibers was evidently quantifiable at naked eye. Afterward, fluorescence quantities have been established on models previously and after coloring cellulose models. Samples were animated using $450 \mathrm{~nm}$ light, which is together absorbed by the undyed fiber and the dye fiber. Consequences are showing in Figure $4^{10}$.

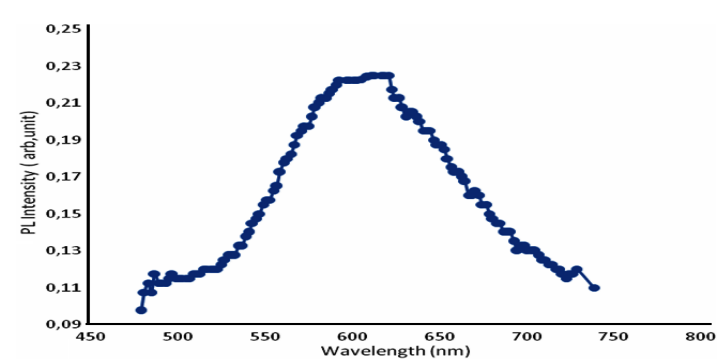

Fig. 4. Production spectra of cellulose fiber colored with date pits extract

The production spectra of the non-dyed cellulose fiber do not demonstrate any band in the visible section. In the opposing, colored cellulose textile existing motivating photoluminescence characters and the maximum value was noted at $672 \mathrm{~nm}$. The divergence may be a importance of connections established between the cellulose and the colorant. Similarly, evaluation of the emission bands from colored and non-colored samples permitted assigning the ipsochromic emission to cellulose textile and the bathochromic one to colorant ${ }^{10}$.

\section{CONCLUSION}

The purpose of this work is to estimate the fluorescence characters of cellulose textile colored with date pits extract, natural colorant. It was creating that colored samples existing motivating photoluminescence characters.

\section{ACKNOWLEDGEMENT}

This research was supported by the Deanship of Scientific Research, Imam Mohammad Ibn Saud Islamic University, Saudi Arabia, Grant No. (19-12-12-005).

\section{Conflict of interest}

The author declare that we have no conflict of interest.

\section{REFERENCES}

1. Guesmi A.; Ladhari N.; Ben hamadi N.; Sakli F. Isolation, identification and dyeing studies of betanin on modified acrylic fabrics. Ind Crop Prod., 2012, 37, 342-346.

2. Guesmi, A.; Ben Hamadi N.; Ladhari, N.; Sakli, F., Dyeing properties and colour fastness of wool dyed with indicaxanthin natural dye. Ind. Crop. Prod., 2012, 37, 493-499.
3. Guesmi, A.; Ben hamadi, N.; Ladhari, N.; Sakli, F., Sonicator dyeing of modified acrylic fabrics with indicaxanthin natural dye. Ind. Crop. Prod., 2013, 42, 63-69.

4. Guesmi, A.; Ladhari, N.; Ben hamadi, N.; Msaddek, M.; Sakli, F., First application of chlorophyll-a as biomordant: sonicator dyeing of wool with betanin dye. J. Clean. Prod., 2013, 39, 97-104. 
5. Guesmi A.; Ladhari N.; Sakli F. Ultrasonic preparation of cationic cotton and its application in ultrasonic natural dyeing. Ultrasonics Sonochemistry., 2013, 20, 571-579.

6. Souissi, M. Guesmi, A. Moussa, A. Valorization of natural dye extracted from date palm pits (Phoenix dactylifera) for dyeing of cotton fabric. Part 2: Optimization of dyeing process and improvement of colorfastness with biological mordants. Journal of Cleaner Production., 2018, 204, 1143-1153.

7. Souissi, M. Guesmi, A. Moussa, Valorization of natural dye extracted from date palm pits (Phoenix dactylifera) for dyeing of cotton fabric. Part 1: Optimization of extraction process using Taguchi design. Journal of Cleaner Production., 2018, 202, 1045-1055.

8. Aldhaheri, A.; Alhadrami, G.; Aboalnaga, N.; Wasfi, I.; Elridi, M., Chemical composition of date pits and reproductive hormonal status of rats fed date pits. Food Chemistry., 2004.
86, 93-97.

9. Nehdi, I.; Omri, S.; Khalil, M.I.; Al-Resayes, S.I. Characteristics and chemical composition of date palm (Phoenix canariensis) seeds and seed oil. Industrial Crops and Products., 2010, 32, 360-365.

10. Guesmi.; A. Ben Hamadi.; N. Ladhari.; N. Saidi.; F. Maaref, H. Sakli.; F. Spectral characterization of wool fabric dyed with indicaxanthin natural dye: Study of the fluorescence property. Industrial Crops and Products., 2013, 46, 264-267.

11. Guesmi A. Ben Hamadi N. Study on optimizing dyeing of cotton using date pits extract as a combined source of coloring matter and biomordant Nat Prod Res., 2019, 32, 810-814.

12. Dhahri, H.; Guesmi, A.; Ben Hamadi, N. Application of phenolic compounds as natural dye extracted from date-pits: dyeing studies of modified acrylic fibres. Nat Prod Res., 2018, 32, 1329-1333. 